\title{
In Memoriam Mario Comporti 1935-2014 (Co-Editor-IN-CHIEF SINCE 2009)
}

\section{Alfonso Pompella, ${ }^{1}$ Angiolo Benedetti,, Rodolfo Bracci, ${ }^{3}$ Gianmichele Galassi ${ }^{4}$}

\author{
${ }^{1}$ Department of Translational Research NTMS, University of Pisa Medical School, Italy; \\ ${ }^{2}$ Department of Molecular and Developmental Medicine, University of Siena, Italy; \\ ${ }^{3}$ Board Member of Accademia dei Fisiocritici, Siena; ${ }^{4}$ Editor-in-Chief (on behalf of the Editorial Board)
}

Mario Comporti was born in Siena and earned a high school diploma (Classical studies) at the local Liceo Classico Enea Silvio Piccolomini. He was proud of this title, and always firmly considered classical studies an essential aspect in the education of young generations. Mario attended as a student at the University of Siena the Institute of Medical Pathology managed by Cesare Bartorelli, and was positively impressed by the ability of many physicians of the Institute to connect the scientific research with the medical-care activity. That was the time period when research first captivated him, to follow him for the rest of his subsequent life. Comporti graduated with honours in 1960, and then worked as Assistant professor at the Institutes of General Pathology of Siena and Turin. In 1966 he was Research Associate at the Department of Physiology of the University of Tennessee, US. He moved in 1968 to the University of Pisa, where he was first Assistant professor and then Full Professor and Director at the Institute of General Pathology. In 1973 he moved to the University of Siena, where he was appointed Director of the Institute of General Pathology. In 1999, following the replacement of Institutes with Departments, Comporti was the Director of the Dept. of Physiopathology and Experimental Medicine till 2005. He retired in 2010. He was Regional Director of the National Foundation for Cancer Research (NFCR) from 1979 to 1986, and then of the Association for International Cancer Research (AICR). Comporti was a member of NATO Science Committee and Visiting professor at the J.A.Burns School of Medicine, US. He was awarded with Gold Medal of Merit for Culture and Science by the Italian Ministry of Education, and was the President of the Italian Society of Pathology for two terms of office. He was a member of the Editorial Board of important international journals as well as a Honorary Member of the Oxygen Club of California. He served as reviewer for illustrious international journals and was popular for his ability to fairly evaluate the others' works.

Freshly graduated, in 1965, Mario Comporti published two pieces of research whose titles were 'Inhibition of lipid peroxidation by $\mathrm{CCL}_{4}$ in vitro and in vivo' and 'Stimulation of the lipid peroxidation of rat liver homogenates by low concentration of $\mathrm{CCL}_{4}$ in vitro' respectively. These pa- pers represent the original observation about the unsuspected relationship between certain hepatotoxic chemicals and lipid peroxidation. It should be noted that in the latter of the aforementioned publications only Comporti's name appears, and that the co-author of the former did not publish any further work on this subject. Therefore, Comporti alone sensed the importance of a phenomenon that now - half a century later - we know to be involved in a multitude of pathological processes, such as atherosclerosis, cell death, carcinogenesis, etc. The concept embodied in that phenomenon subsequently expanded, and has been then globally interpreted as 'oxidative stress'. In the newborn child, oxidative stress is at the root of many serious complications of prematurity such as retinopa-

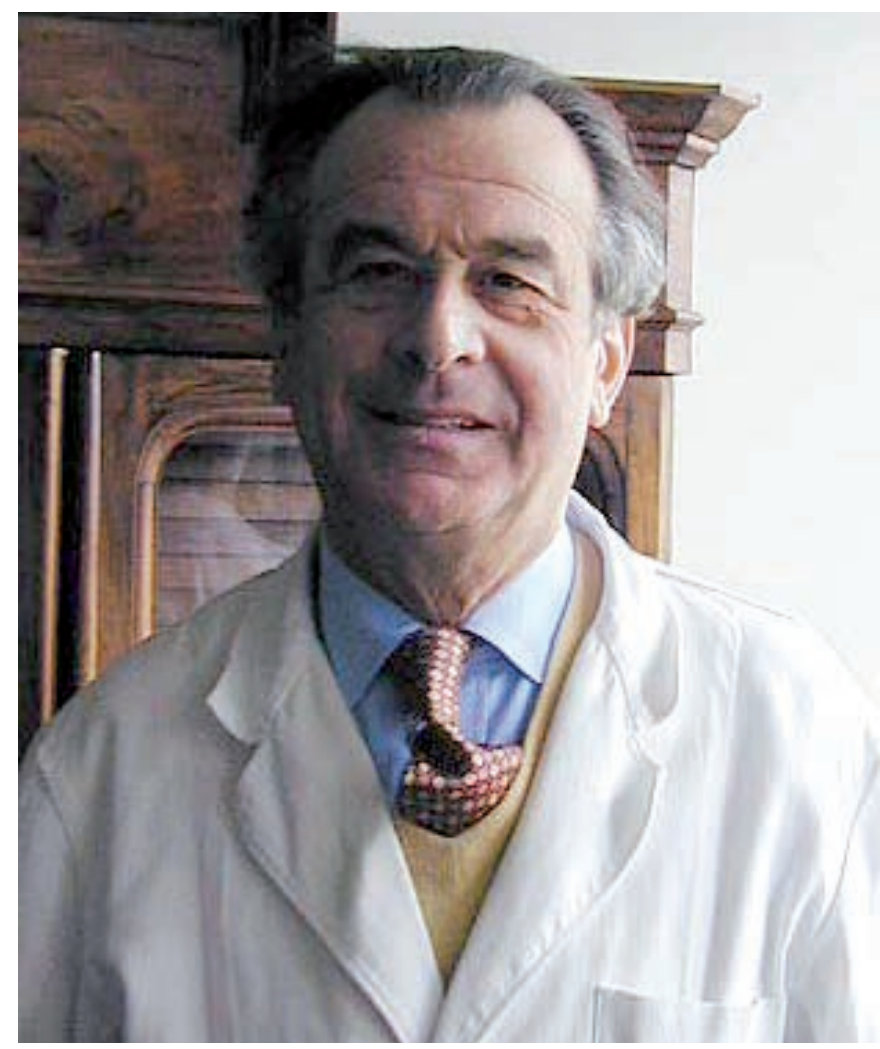

Mario Comporti. 
thy, anoxic-ischemic and haemorrhagic brain injury, and bronchiolar-pulmonary dysplasia.

Once he had settled in Pisa at the beginning of 1970's Mario could build up his own research team, including three young and enthusiast co-workers: Angiolo Benedetti, Alessandro Casini - both MD's - and Marco Ferrali, PhD. The intense experimental studies carried out during the following decade by these four - with the help of several who gradually joined the group after moving to the Institute in Siena - led to a series of crucial observations concerning the mechanisms in initiation, propagation as well as termination of phospholipid peroxidation in the liver and other tissues of living animals. At that time one major focus of the research was the formation of diene conjugates in polyunsaturated fatty acids of cell membranes. This led Mario to establish scientific contacts with other scientists active in the same field, among which a leading position was then occupied by Richard O. Recknagel of Case Western University, Cleveland; close scientific as well as human exchanges thus started between the two, including several visits to the respective labs. Those were years of intense and passionate research work, and the atmosphere at the Institute truly was one of elation. Identification of the molecular species originating from degradation of peroxidised membrane phospholipids became soon a major research objective: mostly a matter of painstakingly accurate chromatographic separations, whose results were detailed in a series of timely publications. It was thus observed that products originating during phospholipid peroxidation were carbonyls in nature, and sufficiently stable to diffuse through a dialysis membrane and produce cytotoxic effects at a distance. Crucial scientific contacts had been established through the NFCR network: among those Trevor F. Slater at Brunel University (Uxbridge, UK), the free radical research pioneer who first identified trichloromethyl radical as the bioactivation metabolite of carbon tetrachloride capable of initiating toxic lipid peroxidation. After learning of a specific dialysable compound under investigation in Siena, it was T.F. Slater to suggest Mario Comporti to establish a collaboration with another NFCR scientist: the biochemist and aldehyde chemistry expert Hermann Esterbauer at the Karl Fraenzens University of Graz, Austria. It was thanks to that most fruitful collaboration that the main cytotoxic product of the phospholipid peroxidation occurring in cellular matter (microsomes) was finally identified as 4-hydroxynonenal (4HNE). That one indeed was the first demonstration that this fatty aldehyde - until then just known as a toxic/carcinogenic chemical deriving from the in vitro degradation of linoleic acid esters - was actually also forming as an endogenous product of lipid peroxidation in biological material. The seminal paper reporting those results (Benedetti et al. 1980) has received to date several hundreds of citations, and in years the finding originated a wealth of research studies in the most varied fields of human pathology as well as biomedical research in general.

Thus, at the beginning of 1980 's, a core of experimental results in pathophysiology of lipid peroxidation was established, representing the conclusion of a first exciting phase in the scientific evolvement of Mario Comporti and his close co-workers. Time was then ripe for a second phase, in which Mario was to assume a role of supervisor for the novel perspectives stemming out from that original core - all of which variably related to redox equilibria and oxidative stress. By then the members of Mario's original team were ready to assume the responsibility of separate labs, each dealing with its own independent research line. Thus A. Benedetti, with younger co-worker R. Fulceri and their students, took the start from the effects of lipid peroxidation on cellular compartmentation of ionic calcium and moved on to investigate the minute details of IP3mediated mechanisms at the endoplasmic reticulum level. M. Ferrali with L. Ciccoli focused on the roles played by redox-active iron in mediating oxidative reactions, with special reference to pathophysiology of erythrocytes. As a result of scientific collaboration with the neonatologists at the University of Siena, important studies were published on preterm infant anaemia. These were among the first investigations on oxidative stress in the newborn, a topic soon expanded by fruitful researches on neonatal brain damage. Research by A.F. Casini, with his students E. Maellaro and A. Pompella, was dedicated to the pathophysiology of cellular glutathione as well as characterization of glutathionedepending enzymes. Other research lines were centered on lung oxidative stress and fibrosis (G. Lungarella, C. Gardi), and lately on $\mathrm{F}_{2}$-isoprostanes (C. Signorini). In most of the papers originating from the individual lines during this second phase Mario Comporti was continuously contributing his personal views as far as study design, discussion of results and preparation of manuscripts. The stringency, the absolute and tireless accuracy he would dedicate to these fundamental preparatory steps will represent a formidable example for a long time. His close co-workers will always preserve the memory of his office, his neatly ordered collection of reprints and photocopies, his working notes rigorously written with a pencil on half-folded sheets of paper in his peculiar angular, spiky - but anyhow fully legible handwriting.

At the turn of the 3rd millennium Mario was thus increasingly assuming the role of a senior mentor, peacefully intent to closely follow and enjoy the successes of his by then numerous followers. His inner good-natured, at times playful personality became gradually more apparent, more often than previously. Nevertheless his own personal impetus for active research was by no means dormant. Rather, with the help of younger co-workers, till the very last times before his retirement he could personally carry out experimental studies focused on pathophysiology of the newly described lipid 
peroxidation products $\mathrm{F}_{2}$-isoprostanes. The description of signalling pathways activated by these compounds in liver fibrosis was the subject of his own few last publications.

Mario Comporti was also a great poet, as it was mentioned on the occasion of a commemorative day in honour of the poet Mario Luzi. The two knew each other, and their love for poetry was so great that they became very good friends. Mention of the opinion of Mario Luzi about Mario Comporti's poetry is opportune: 'There is a preliminary choice, a deliberate and logical proposition of fidelity to consecrated and revered values in Comporti's writing. It is nice to see how this choice is rewarded by the inner creation of the artist, how his secret creative impulse hovers and his thoughts search for their profundity. It is nice to see how such a liberal discipline is confirmed and improved by the perseverance of a vocation, besides the great technical skills. Therefore we must acknowledge and be proud of the value of his work. I am pleased to do it again.' After Deriva d'orizzonti (1985), Mario's books of poems have been awarded several literary prizes, as proved by the shields that Mario proudly showed in his paternal house in Via di Città, its beloved house where everything had to remain in its place exactly as it was during his childhood. Among those, the literary prize he was awarded at Palazzo Vecchio in Florence by the International Academy 'Le Muse' is to be mentioned. At the National Library of Florence and at the 'Gabinetto Vieusseux' a few poems by Comporti were read before a distinguished audience. In order to understand how a man of science could combine his love for scientific research with poetry, we would better rely on his words. In the preface of his book on oxidative stress, Mario wrote: 'Research actually gives the possibility to create something and this means excitement to me. I decided to become a researcher to live this excitement, because it represents the only way I could get closer to the top of creativity.
Research bewitches me, and makes me feel the same tension towards the absolute that can be reached by means of the most meaningful lyrical, pictorial and musical intuitions and inspirations.'He was also the president of the Sodalizio Amici della Chigiana. It can be stated that Mario was a rare person, able to reach - at a high level - the so-called synthesis between classical and scientific culture.

Mario Comporti was not an unemotional researcher and a detached man of letters. He loved the Palio and did not disdain to follow the parade of the Contrada della Giraffa after its victory in August 1997. Since a log time, Mario Comporti was in the Board of the Accademia dei Fisiocritici and in 2007 he suggested the renewal of the ancient Atti dell'Accademia dei Fisiocritici - founded in 1761 - by introducing English language as in all other contemporary scientific journals. His proposal was accepted, and he became Editor in Chief of the new Atti; the first issue of the new publication, renamed Journal of Siena Academy of Sciences, was published in 2009. He was a fan of Siena Football Club when it was in Serie $A$, and he followed the championship competently. He was never superficial or sectarian, with his deep literary, historical, artistic and musical culture, with his jokes, impersonations, and by proposing absurd but subtle comparisons he could always create a peaceful atmosphere with his friends, who now miss him inconsolably. The loss of Mario Comporti has been tremendous not only for his pupils and friends, who understood and loved him, but also for the life itself of this Academy.

\section{REFERENCE}

Benedetti A, Comporti M, Esterbauer H. Identification of 4-hydroxynonenal as a cytotoxic product originating from the peroxidation of liver microsomal lipids. Biochim Biophys Acta 1980;620:281-96. 